4 SOLVD Investigators. Effect of enalapril on survival in patients with reduced left ventricular ejection fractions and congestive heart failure. $N$ Engl J Med 1991;325:293-302.

5 Pfeffer MA, Braunwald E, Moye LA, Basta L, Brown EJ, Cuddy TE, et al. Effect of captopril on mortality and morbidity in patients with left ventricular dysfunction after myocardial infarction. Results of the survival and ventricular enlargement trial. The SAVE investigators. N Engl J Med 1992:327:669-77.

6 McDonagh TA, Morrison CE, Lawrence A, Ford I, Tunstall-Pedoe H, McMurray JJ, et al. Symptomatic and asymptomatic left-ventricular systolic dysfunction in an urban population. Lancet 1997;350:829-33.

7 Mosterd A, de BM, Hoes AW, Deckers JW, Hofman A, Grobbee DE. Usefulness of echocardiography in detecting left ventricular dysfunction in population-based studies (the Rotterdam study). Am J Cardiol population-based

8 Wendelboe O, Hansen JF, Hilden J. The prevalence of heart failure in relation to a symptom-based diagnosis, echocardiography, and a primary to secondary care-based diagnosis [abstract]. Eur Heart J 1998;19:249.

9 Rose GA, Blackburn H. Minnesota code for resting electrocardiograms. classification of the electrocardiogram for population studies. Circulation 1960;21:137-88

10 Ouinones MA, Waggoner AD, Reduto LA, Nelson JG, Young JB, Winters WL, et al. A new, simplified and accurate method for determining ejection
fraction with two-dimensional echocardiography. Circulation fraction with
$1981 ; 64: 744-53$.

11 Sahn DJ, DeMaria A, Kisslo J, Weyman A. Recommendations regarding quantitation in M-mode echocardiography: results of a survey of echocardiographic measurements. Circulation 1978;58:1072-83

12 Berning J, Rokkedal NJ, Launbjerg J, Fogh J, Mickley H, Andersen PE. Rapid estimation of left ventricular ejection fraction in acute myocardial infarction by echocardiographic wall motion analysis. Cardiology infarction by $1992 ; 80: 257-66$.

13 Kober L, Torp-Pedersen C, Carlsen J, Videbaek R, Egeblad H. An echocardiographic method for selecting high risk patients shortly after acute myocardial infarction, for inclusion in multicentre studies (as used in the TRACE study). Trandolapril cardiac evaluation. Eur Heart J 1994;15:1616-20.
14 Davie AP, Francis CM, Love MP, Caruana L, Starkey IR, Shaw TR, et al. Value of the electrocardiogram in identifying heart failure due to left ventricular systolic dysfunction. BMJ 1996;312:222-5

15 McDonagh TA, Robb SD, Murdoch DR, Morton JJ, Ford I, Morrison CE et al. Biochemical detection of left-ventricular systolic dysfunction. Lancet 1998;351:9-13.

16 Rihal CS, Davis KB, Kennedy JW, Gersh BJ. The utility of clinical, electrocardiographic, and roentgenographic variables in the prediction of left ventricular function. Am J Cardiol 1995;75:220-3.

17 Gillespie ND, McNeill G, Pringle T, Ogston S, Struthers AD, Pringle SD Cross sectional study of contribution of clinical assessment and simple cardiac investigations to diagnosis of left ventricular systolic dysfunction in patients admitted with acute dyspnoea. BMJ 1997:314:936-40.

18 McNamara RF, Carleen E, Moss AJ. Estimating left ventricular ejection fraction after myocardial infarction by various clinical parameters. $\mathrm{Am} \mathrm{J}$ Cardiol 1988; 62:192-6.

19 Silver MT, Rose GA, Paul SD, O'Donnell CJ, O'Gara PT, Eagle KA. A clinical rule to predict preserved left ventricular ejection fraction in patients after myocardial infarction. Ann Intern Med 1994;121:750-6.

20 McClure S, Caruana L, Davie AP, Goldthorp S, McMurray JJ. Cohort study of plasma natriuretic peptides for identifying left ventricular systolic dysfunction in primary care. $B M J$ 1998;317:516-9.

21 McDonagh TA, Morrison CE, McMurray JJV, Dargie HJ. Screening with natriuretic peptides to detect a wall motion score index of $\leqslant 1.2$ [abstract]. Eur Heart J 1997;suppl 19:597.

22 Willenheimer RB, Israelsson BA, Cline CM, Erhardt LR. Simplified echocardiography in the diagnosis of heart failure. Scand Cardiovascular I 1997;31:9-16.

23 Cowie MR, Struthers AD, Wood DA, Coats AJ, Thompson SG, Poole-Wilson PA, et al. Value of natriuretic peptides in assessment of patients with possible new heart failure in primary care. Lancet 1997;350:1349-53

24 Morgan S, Smith H, Simpson I, et al. Prevalence and clinical characteristics of left ventricular dysfunction among elderly patients in general practice setting: cross sectional survey. BMJ 1999;318:368-72.

(Accepted 1 November 1999)

\title{
Evaluation of the effectiveness of an educational intervention for general practitioners in adolescent health care: randomised controlled trial
}

Centre for Adolescent Health, Department of Paediatrics, University of Melbourne, Parkville, Victoria 3052, Australia Lena A Sanci fellow in adolescent health

Carolyn M M Coffey epidemiologist Friederike C M Veit adolescent physician Michael Carr-Gregg director of training and education

George C Patton director

Glenn Bowes professorial fellow

continued over

BMJ 2000;320:224-30

website

extra

The sample size calculation and a chart showing the flow of participants through the trial appears on the BMJ's website

www.bmj.com

\section{A Sanci, C M M Coffey, F C M Veit, M Carr-Gregg, G C Patton, N Day, G Bowes}

\begin{abstract}
Objective To evaluate the effectiveness of an educational intervention in adolescent health designed for general practitioners in accordance with evidence based practice in continuing medical education.

Design Randomised controlled trial with baseline testing and follow up at seven and 13 months. Setting Local communities in metropolitan Melbourne, Australia.

Participants 108 self selected general practitioners. Intervention A multifaceted educational programme for 2.5 hours a week over six weeks on the principles of adolescent health care followed six weeks later by a two hour session of case discussion and debriefing. Outcome measures Objective ratings of consultations with standardised adolescent patients recorded on videotape. Questionnaires completed by the general practitioners were used to measure their knowledge, skill, and self perceived competency, satisfaction with the programme, and self reported change in practice. Results 103 of 108 (95\%) doctors completed all phases of the intervention and evaluation protocol. The intervention group showed significantly greater improvements in all outcomes than the control group at the seven month follow up except for the rapport and satisfaction rating by the standardised patients.
\end{abstract}

$104(96 \%)$ participants found the programme appropriate and relevant. At the 13 month follow up most improvements were sustained, the confidentiality rating by the standardised patients decreased slightly, and the objective assessment of competence further improved. 106 (98\%) participants reported a change in practice attributable to the intervention.

Conclusions General practitioners were willing to complete continuing medical education in adolescent health care and its evaluation. The design of the intervention using evidence based educational strategies proved an effective and quick way to achieve sustainable and large improvements in knowledge, skill, and self perceived competency.

\section{Introduction}

The patterns of health need in youth have changed noticeably over the past three decades. Studies in the United Kingdom, North America, and Australia have shown that young people experience barriers to health services. ${ }^{1-5}$ With the increase in a range of youth health problems, such as depression, eating disorders, drug and alcohol use, unplanned pregnancy, chronic illness, and suicide, there is a need to improve the accessibility and quality of health services to youth. ${ }^{36}$

In the Australian healthcare system general practitioners provide the most accessible primary health 
care for adolescents. ${ }^{7}$ Yet Veit et al surveyed 1000 Victorian general practitioners and found that $80 \%$ reported inadequate undergraduate training in consultation skills and psychosocial diseases in adolescents and $87 \%$ wanted continuing medical education in these areas. ${ }^{4}$ These findings agreed with comparable overseas studies. $^{9-11}$

Evidence based strategies in helping doctors learn and change practice are at the forefront of the design of continuing medical education. ${ }^{12-14}$ In response to the identified gap in training an evidence based educational intervention was designed to improve the knowledge, skill, and self perceived competency of general practitioners in adolescent health. We conducted a randomised controlled trial to evaluate the intervention, with follow up at seven and 13 months after the baseline assessment.

\section{Participants and methods}

The divisions of general practice are regional organisations that survey the needs of, and provide education for, general practitioners in their zone. There are 15 divisions in metropolitan Melbourne. Advertisements inviting participation in our trial were placed in 14 of the 15 divisional and state college newsletters and mailed individually to all division members. The course was free, and continuing medical education points were available. Respondents were sent details of the intervention and the evaluation protocol and asked to return a signed consent form. Divisions and doctors were excluded if they had previously received a course in adolescent health from this institution.

\section{Randomisation}

Consenting doctors were grouped into eight geographical clusters by practice location to minimise contamination and to maximise efficiency of the delivery of the intervention. Clusters (classes) of similar size were randomised to intervention or control by an independent researcher.

\section{Intervention}

The box details the objectives, content, and instructional design of the multifaceted intervention. A panel comprising young people, general practitioners, college education and quality assurance staff, adolescent health experts, and a state youth and family government officer gave advice on the design. ${ }^{15}$ The curriculum included evidence based primary and secondary educational strategies such as role play with feedback, modeling practice with opinion leaders, and the use of checklists. ${ }^{12}{ }^{16}$ The six week programme was delivered concurrently by LS, starting one month after baseline testing (see figure on website).

\section{Measures}

Table 1 summarises the instruments used in the evaluation. Parallel strategies of objective and self reported ratings of knowledge, skill, and competency were used to ensure findings were consistent. ${ }^{17}{ }^{18}$ Participants' satisfaction with the course and their self reported change in practice were evaluated at 13 months. Any other training or education obtained in adolescent health or related areas were noted.
Clinical skills

Seven female drama students were trained to simulate a depressed 15 year old exhibiting health risk behaviour. Case details and performances were standardised according to published protocols ${ }^{19-21}$ and varied for each testing period. Doctors were given 30 minutes to interview the patient in a consulting room at this institution. An unattended camera recorded the consultation on videotape.

The standardised patients were trained in the use of a validated rating chart ${ }^{21}$ assessing their own rapport and satisfaction and discussion about confidentiality. These were completed after the interview while still in role. They were blind to the intervention status of the doctors, and no doctor had the same patient for successive interviews.

Goals, content, and instructional design of intervention in principles of adolescent health care for general practitioners

\section{Intervention goals}

- To improve general practitioners' knowledge, skill, and attitudes in the generic concepts of adolescent health to effectively gain rapport with young people, screen them for health risk, and provide health promotion and appropriate management plans

- To increase awareness of the barriers their practices may pose for youth access and how these may be overcome

- To understand how other services can contribute to the management of young people and how to access these in their locality

Intervention content (weekly topics)

- Understanding adolescent development, concerns, and current morbidities, the nature of general practice, and yourself

- Locating other youth health services and understanding how they work, and medicolegal and ethical issues in dealing with minors

- Communication and consultation skills and health risk screening

- Risk assessment of depression and suicide

- Detection and initial management of eating disorders

Instructional design

Needs analysis

- From previous surveys and informally at start of workshops

Primary educational strategy

Workshops for 2.5 hours weekly for six weeks

- Debriefing from previous session

- Brief didactic overviews

- Group problem based activities and discussion

- Modeling of interview skills by opinion leaders on instructional video

- Role play and feedback practice sessions with adolescent actors

- Activities set to practise in intervening week

- Individual feedback on precourse evaluation video

Course book

- Goals, objectives, course requirements, and notes

- Suggested further reading

- Class or home activities with rationale for each

Resource book

- Reading material expanding on workshop sessions

Practice reinforcing and enabling strategies

- Adolescent assessment chart for patient audit

- Logbook for reflection on experience with the patients audited

- Self assembled list of adolescent health services in local community

- Availabilty of tutor (LS) by phone for professional support between workshops

- Refresher session for group discussion of experiences in practice (six weeks after course) 
Two independent observers, blind to participants' status, assessed the taped consultations in the three testing periods. A doctor in adolescent health coded three items in the scale relating to medical decision making. A trained non-medical researcher assessed all other items. The chart was developed from two validated instruments for assessment of adolescent consultations $^{21}$ and general practice consultations. ${ }^{22} 23$ Marks for both competency and content of the health risk assessment were summarised into a percentage score. The same observers were used in all three testing periods.

\section{Self perceived competency}

Two questionnaires were developed for the doctors to rate both their comfort and their knowledge or skill with process issues, including the clinical approach to adolescents and their families and with substantive issues of depression, suicide risk assessment, alcohol and drug issues, eating disorders, sexual history taking, and sexual abuse. Doctors also rated their consultation with the standardised patient on a validated chart, ${ }^{21}$ itemising their self perceived knowledge and skill.

\section{Knowledge}

Knowledge was assessed with short answer and multiple choice items developed to reflect the workshop topics. The items were pretested and refined for contextual and content validity. The course tutor, blind to group status, awarded a summary score.

\section{Analysis}

Statistical analysis was performed with STATA (Stata, Texas), with the individual as the unit of analysis. Factor analysis with varimax rotation was used to identify two domains within the comfort and self perceived knowledge or skill items: process and substantive issues. The internal consistency for all scales was estimated using Crohnbach's $\alpha$. Reproducibility within and between raters was estimated with one way analysis of variance

Table 1 Evaluation measures, their content, inter item reliability, and intraclass correlation within randomisation groups estimated at baseline

\begin{tabular}{|c|c|c|c|}
\hline Evaluation measures & Content† & Crohnbach $\alpha$. & $\begin{array}{l}\text { Intraclass } \\
\text { correlation }\end{array}$ \\
\hline \multicolumn{4}{|l|}{ Skills } \\
\hline \multicolumn{4}{|l|}{ Patients' rating: } \\
\hline Satisfaction and rapport & 7 & 0.95 & 0.01 \\
\hline Confidentiality discussion & 1 & - & 0.07 \\
\hline \multicolumn{4}{|l|}{ Observer's rating: } \\
\hline Competency* & 13 & 0.95 & 0.05 \\
\hline Content of risk assessment ${ }^{*}$ & 22 items & - & 0.09 \\
\hline \multicolumn{4}{|l|}{ Self perceived competency } \\
\hline \multicolumn{4}{|l|}{ Comfort: } \\
\hline Clinical process & 11 & 0.88 & $<0.01$ \\
\hline Substantive issues & 10 & 0.93 & 0.01 \\
\hline \multicolumn{4}{|l|}{ Self perceived knowledge and skill: } \\
\hline Clinical process & 11 & 0.90 & 0.04 \\
\hline Substantive issues & 10 & 0.94 & 0.05 \\
\hline $\begin{array}{l}\text { General practitioner's self } \\
\text { score on interview }\end{array}$ & 6 & 0.93 & $<0.01$ \\
\hline \multicolumn{4}{|l|}{ Knowledge } \\
\hline Self completion knowledge test & 41 items & - & $<0.01$ \\
\hline
\end{tabular}

Table 2 Demographic characteristics of general practitioners by intervention group. Numbers are percentages

\begin{tabular}{|c|c|c|}
\hline Characteristic & $\begin{array}{l}\text { Intervention group } \\
(\mathrm{n}=54)\end{array}$ & $\begin{array}{c}\text { Control group } \\
(n=51)\end{array}$ \\
\hline Male & $24(44)$ & $28(55)$ \\
\hline \multicolumn{3}{|l|}{ Age (years) } \\
\hline $25-34$ & $13(24)$ & $10(20)$ \\
\hline $35-44$ & $20(37)$ & $16(31)$ \\
\hline $45-54$ & $18(33)$ & $15(29)$ \\
\hline$\geqslant 55$ & $3(6)$ & $10(20)$ \\
\hline Language other than English spoken & $14(26)$ & $24(47)$ \\
\hline \multicolumn{3}{|l|}{ Average hours consulting/week: } \\
\hline$<20$ & $17(31)$ & $20(20)$ \\
\hline $20-40$ & $29(54)$ & $22(44)$ \\
\hline $41-60$ & $8(15)$ & $18(36)$ \\
\hline \multicolumn{3}{|l|}{ Patients seen in average week: } \\
\hline$<50$ & $14(26)$ & $9(18)$ \\
\hline $51-100$ & $16(28)$ & $13(26)$ \\
\hline $101-150$ & $18(33)$ & $16(32)$ \\
\hline$>150$ & $7(13)$ & $12(24)$ \\
\hline \multicolumn{3}{|c|}{$\%$ of adolescents of total patients seen per week: } \\
\hline$<10$ & $24(45)$ & $21(41)$ \\
\hline $10-30$ & $22(40)$ & $23(43)$ \\
\hline$>30$ & $8(15)$ & $8(16)$ \\
\hline \multicolumn{3}{|l|}{ Age (years) of oldest child: } \\
\hline No children & $3(6)$ & $9(18)$ \\
\hline$\leqslant 10$ & $19(35)$ & $12(24)$ \\
\hline $11-20$ & $21(39)$ & $10(20)$ \\
\hline$>20$ & $11(20)$ & $19(38)$ \\
\hline Vocational registration & $51(94)$ & $46(90)$ \\
\hline College exams taken & $25(46)$ & $15(29)$ \\
\hline Previous training in adolescent health & $15(28)$ & $15(29)$ \\
\hline \multicolumn{3}{|l|}{ Type of practice: } \\
\hline Solo & $4(7)$ & $13(25)$ \\
\hline Group & $43(80)$ & $24(47)$ \\
\hline Community health centre & 0 & $4(8)$ \\
\hline Extended hours & 0 & $2(4)$ \\
\hline Other & $7(13)$ & $8(16)$ \\
\hline \multicolumn{3}{|l|}{ Appointments/hour: } \\
\hline$\leqslant 4$ & $32(59)$ & $33(65)$ \\
\hline $5-6$ & $9(17)$ & $4(8)$ \\
\hline$\geqslant 6$ & $8(15)$ & $8(16)$ \\
\hline Other booking systems & $5(9)$ & $6(12)$ \\
\hline
\end{tabular}

as was the intraclass correlation of baseline score within each teaching group.

The effect of this intervention was evaluated by regression of gain scores (score at seven month follow up minus baseline score) on the intervention status, with adjustment for baseline and potential confounding variables. Robust standard errors were used to allow for randomisation by cluster. The sustainability of outcome changes in the intervention group between the assessments at seven months and 13 months was evaluated with paired $t$ tests.

\section{Results}

\section{Participants}

Newsletters and mailed advertisements to 2415 general practitioners resulted in 264 expressions of interest. Overall, 139 doctors gave written consent to be randomised. Attrition after notification of study status left $55(73 \%)$ doctors in the intervention group and $53(83 \%)$ in the control group, with an average of 13.5 (12 to 15$)$ doctors in each class.

The age and country of graduation of the doctors in this study were similar to the national workforce of 
Table 3 Multiple regression analyses of baseline and difference in scores on continuous outcome measures evaluating success of educational intervention at seven month follow up. Models include gender, age group, language other than English, type of practice, average hours worked per week, and college exams taken. Difference scores are also adjusted for baseline score and training obtained from elsewhere over 7 month period. Robust standard errors allowed for cluster randomisation. All scores out of 100

\begin{tabular}{|c|c|c|c|c|c|}
\hline \multirow[b]{2}{*}{ Scores } & \multirow[b]{2}{*}{ No* } & \multirow{2}{*}{$\begin{array}{c}\text { Baseline } \\
\text { Mean }(95 \% \mathrm{CI})\end{array}$} & \multicolumn{2}{|c|}{ Difference at 7 month follow up } & \multirow[b]{2}{*}{$P$ value } \\
\hline & & & Mean $(95 \% \mathrm{Cl})$ & Effect size & \\
\hline \multicolumn{6}{|l|}{ Skills } \\
\hline \multicolumn{6}{|c|}{ Standardised patients' rapport and satisfaction: } \\
\hline Control & 50 & $67.9(61.4$ to 74.5$)$ & $-0.5(-6.1$ to 5.0$)$ & -0.02 & \multirow{2}{*}{0.12} \\
\hline Intervention & 54 & 67.9 (64.9 to 70.9$)$ & 6.0 (2.6 to 9.5$)$ & 0.54 & \\
\hline \multicolumn{6}{|c|}{ Standardised patients' confidentiality: } \\
\hline Control & 50 & $35.2(29.3$ to 41.1$)$ & $4.0(-10.3$ to 18.3$)$ & 0.19 & \multirow{2}{*}{$<0.01$} \\
\hline Intervention & 54 & $42.2(31.0$ to 53.4$)$ & 53.5 (49.3 to 57.8$)$ & 1.28 & \\
\hline \multicolumn{6}{|c|}{ Observer competence: } \\
\hline Control & 50 & 51.8 (45.9 to 57.6$)$ & $2.6(-3.0$ to 8.1$)$ & 0.12 & \multirow{2}{*}{0.01} \\
\hline Intervention & 54 & $48.8(46.2$ to 51.4$)$ & $15.3(11.1$ to 19.5$)$ & 1.55 & \\
\hline \multicolumn{6}{|c|}{ Observer risk assessment: } \\
\hline Control & 50 & 53.3 (49.4 to 57.2$)$ & $0.5(-3.0$ to 4.1$)$ & 0.04 & \multirow{2}{*}{0.03} \\
\hline Intervention & 53 & 50.7 (44.2 to 57.2$)$ & 9.9 (5.8 to 14.0$)$ & 0.41 & \\
\hline \multicolumn{6}{|c|}{ Self perceived competency } \\
\hline \multicolumn{6}{|c|}{ Comfort (process): } \\
\hline Control & 49 & 71.1 (66.4 to 75.8$)$ & $0.2(-3.5$ to 4.0$)$ & 0.01 & \multirow{2}{*}{0.03} \\
\hline Intervention & 54 & 71.8 (69.7 to 73.9$)$ & 7.1 (4.7 to 9.4$)$ & 0.89 & \\
\hline \multicolumn{6}{|c|}{ Comfort (substantive): } \\
\hline Control & 50 & 58.1 (52.3 to 63.9) & $0.3(-5.1$ to 5.6$)$ & 0.01 & \multirow{2}{*}{$<0.01$} \\
\hline Intervention & 54 & 60.5 (56.1 to 64.8$)$ & $15.8(13.8$ to 17.8$)$ & 0.97 & \\
\hline \multicolumn{6}{|c|}{ Knowledge and skill (process): } \\
\hline Control & 50 & 65.9 (60.4 to 71.5$)$ & $0.7(-4.0$ to 5.3$)$ & 0.03 & \multirow{2}{*}{$<0.01$} \\
\hline Intervention & 53 & $66.3(63.6$ to 69.1$)$ & 15.6 (12.1 to 19.2$)$ & 1.54 & \\
\hline \multicolumn{6}{|c|}{ Knowledge and skill (substantive): } \\
\hline Control & 50 & 52.1 (44.5 to 59.7$)$ & $2.8(-2.0$ to 7.6$)$ & 0.10 & \multirow{2}{*}{$<0.01$} \\
\hline Intervention & 54 & 57.5 (53.8 to 61.2$)$ & 20.6 (18.2 to 22.9) & 1.50 & \\
\hline \multicolumn{6}{|c|}{ Doctors' self rating on taped consultation } \\
\hline Control & 49 & 56.6 (52.7 to 60.5$)$ & $3.1(0.6$ to 5.6$)$ & 0.22 & \multirow{2}{*}{$<0.01$} \\
\hline Intervention & 54 & 56.9 (55.7 to 58.1$)$ & $17.8(15.9$ to 19.7$)$ & 4.01 & \\
\hline \multicolumn{6}{|l|}{ Knowledge test } \\
\hline Control & 49 & 33.3 (31.6 to 35.0$)$ & $3.1(0.6$ to 5.6$)$ & 0.51 & \multirow{2}{*}{$<0.01$} \\
\hline Intervention & 54 & 32.8 (31.6 to 34.0$)$ & 14.6 (13.0 to 16.2$)$ & 3.31 & \\
\hline
\end{tabular}

*Variations due to missing values in rating forms of some participants.

Table 4 Evaluation of change in unadjusted percentage scores for intervention group $(n=54)$ from baseline to seven month follow up and from 7 month to 13 month follow up using paired $t$ tests. Values are mean $(95 \% \mathrm{Cl})$ unless stated otherwise

\begin{tabular}{|c|c|c|c|c|c|}
\hline \multirow[b]{2}{*}{ Scores } & \multirow[b]{2}{*}{ Baseline } & \multicolumn{2}{|c|}{ Follow up } & \multirow[b]{2}{*}{ P value* } & \multirow[b]{2}{*}{$P$ value } \\
\hline & & 7 months & 13 months & & \\
\hline \multicolumn{6}{|l|}{ Skills } \\
\hline Standardised patients' rapport and satisfaction & 68.6 (63.5 to 73.7$)$ & 76.0 (71.7 to 80.2$)$ & 75.9 (71.4 to 80.5$)$ & $<0.01$ & 1.00 \\
\hline Standardised patients' confidentiality & 42.5 (34.4 to 50.6$)$ & 92.7 (89.1 to 96.3$)$ & 84.4 (78.4 to 90.5$)$ & $<0.01$ & 0.01 \\
\hline Observer competence & $51.0(46.3$ to 55.8$)$ & $65.3(60.3$ to 70.3$)$ & 70.7 (66.3 to 75.0$)$ & $<0.01$ & 0.02 \\
\hline Observer risk assessment & $51.2(47.9$ to 54.5$)$ & 61.3 (58.4 to 64.3$)$ & 61.4 (58.3 to 64.4) & $<0.01$ & 1.00 \\
\hline \multicolumn{6}{|l|}{ Self perceived competency } \\
\hline \multicolumn{6}{|l|}{ Comfort: } \\
\hline Process & $71.3(67.8$ to 74.8$)$ & 78.1 (74.8 to 81.5$)$ & 80.0 (77.3 to 82.7$)$ & $<0.01$ & 0.12 \\
\hline Substantive & 59.6 (55.4 to 63.9$)$ & $74.9(71.7$ to 78.0$)$ & 75.5 (72.4 to 78.7$)$ & $<0.01$ & 0.58 \\
\hline \multicolumn{6}{|l|}{ Self perceived knowledge and skill: } \\
\hline Process & 66.6 (63.4 to 69.7$)$ & 80.8 (78.1 to 83.5$)$ & 81.9 (79.2 to 84.6$)$ & $<0.01$ & 0.27 \\
\hline Substantive & 56.7 (52.8 to 60.6) & 76.3 (73.2 to 79.5$)$ & 76.3 (73.0 to 79.6$)$ & $<0.01$ & 0.99 \\
\hline $\begin{array}{l}\text { General practitioner self rating on taped } \\
\text { consultation }\end{array}$ & 55.6 (50.6 to 60.6$)$ & 72.1 (68.7 to 75.6$)$ & 71.0 (67.3 to 74.7$)$ & $<0.01$ & 0.59 \\
\hline Knowledge test & 33.5 (31.5 to 35.4$)$ & 48.0 (46.1 to 49.9$)$ & 47.7 (45.8 to 49.6$)$ & $<0.01$ & 0.71 \\
\hline
\end{tabular}

*Baseline to 13 months.

†-13 months.

general practitioners. ${ }^{24}{ }^{25}$ Female doctors were overrepresented (50\% in this study versus $19 \%$ and $33 \%$ in the other reports). Table 2 describes the randomisation groups. There was imbalance in age, gender, languages other than English spoken, average weekly hours of consulting, types of practice, and college examinations.

\section{Compliance}

One doctor dropped out of the intervention group. Overall, 44 doctors attended all six tutorials, eight missed one, and two missed three. In total, 103 of 108 $(95 \%)$ of participants at baseline completed the entire evaluation protocol (see website). 


\section{Measures}

The evaluation scales showed satisfactory internal consistency and low association with class membership (table 1). Satisfactory interrater agreement was achieved on the competency scale $(\mathrm{n}=70, r=0.70)$. The intrarater consistency for both medical and non-medical raters was also satisfactory $(\mathrm{n}=20$, $r=0.80$ and 0.91 respectively).

\section{Effect of the intervention}

Table 3 describes the baseline measures and the effect of the intervention at the seven month follow up. All analyses were adjusted for age, gender, languages other than English, average weekly hours of consulting, practice type, and college examinations. Doctors reporting education in related areas during follow up $(67 \%$ control (34 of 51), 41\% intervention (22 of 54)) were characterised. The difference analysis was adjusted for this extraneous training and baseline score, although the extraneous training did not affect any outcomes. The study groups were similar on all measures at baseline. The intervention group showed significantly greater improvements than the control group at the seven month follow up in all outcomes except the rapport rating by the standardised patients.

The contextual validity and applicability of the course was assessed by 48 of 53 doctors and rated positively by $46(96 \%)$.

Follow up of the intervention group at 13 months The intervention effect was sustained in most measures and further improved in the independent rater's assessment of competence (table 4). The crude rating of the confidentiality discussion by the standardised patients deteriorated at the 13 month assessment but was significantly greater than baseline. Overall, $98 \%$ of the participants reported a change in practice, which they attributed to the intervention.

\section{Discussion}

A course in adolescent health for six sessions designed with evidence based strategies in doctor education brought substantial gains in knowledge, skills, and self perceived competency of the intervention group of doctors compared with the control group, except for the rapport and satisfaction rating by the standardised patients. The changes were generally sustained over 12 months and further improved in the independent observer's rating of competence. Almost all participants reported a change in actual practice since the intervention.

These results are better than reported in a review of 99 randomised controlled trials to evaluate continuing medical education published from 1974-95. ${ }^{12}$ Although over $60 \%$ had positive outcomes they were small to moderate and usually in only one or two outcome measures. In keeping with the recommendations of this review we adapted a rigorous design, clearly defined our target population, and used multiple methods for evaluating competence. Perhaps more importantly the intervention design incorporated three further elements: the use of evidence based educational strategies, a comprehensive preliminary needs analysis, and the content validity of the curriculum ensured by the involvement of both young people and doctors.
- Firm evidence shows that the confidence, knowledge, and skills of doctors in adolescent health contribute to barriers in delivering health care to youth

- Evidence based strategies in continuing medical education were used in the design of a training programme to address the needs of doctors and youth

- The programme covered adolescent development, consultation and communication skills, health risk screening, health promotion, risk assessment of depression and suicide, and issues in management of psychosocial health risk including interdisciplinary approaches to care

- Most interested doctors attended and completed the 15 hour training programme over six weeks and the evaluation protocol covering 13 months

- Doctors completing the training had substantial gains in knowledge, clinical skills, and self perceived competency than the controls; these gains were sustained at 12 months and were further improved in the objective measure of clinical competence in conducting a psychosocial interview

The participants clearly represented a highly motivated group of doctors. This self selection bias was unavoidable but reflected the reality that only interested doctors would desire special skills in this domain and conforms to the adult learning principle of providing education where there is a self perceived need and desire for training. ${ }^{12}{ }^{26}{ }^{27}$ We therefore established that the intervention is effective with motivated doctors. It is generally accepted that doctors with an interest in a topic would already have high levels of knowledge and skill, with little scope for improvement. This was not the case in our study. Baseline measures were often low and improvements were large, confirming the need for professional development in adolescent health. The retention rate was excellent and possibly due, in part, to the role of a doctor in the design of the programme, in recruitment, and in tutoring.

Doubt remains as to whether improved competency in a controlled test setting translates to improved performance in clinical practice. ${ }^{28}$ High competency ratings are not necessarily associated with high performance, but low competency is usually associated with low performance. ${ }^{16} 2930$

The rapport and satisfaction rating by the standardised patients was the only outcome measure apparently unresponsive to the intervention. Actors' ratings and character portrayal were standardised, and gender bias was controlled by using only actresses. Even with these precautions three actresses scored differently from the rest, one had fewer physician encounters, and the subjective nature of the rating scale probably contributed to large individual variation. A trend towards improvement in the intervention group was noted but our study lacked sufficient power to find a difference. In other settings validity and reliability in competency 
assessments with standardised patients has been shown to increase with the number of consultations examined. $^{31} 32$ Pragmatically, it was not feasible to measure multiple consultations in our study.

Errors in interrater measurement were minimised by using the same raters for all three periods of testing. The independent observer and patient were blind to study status but may have recognised the intervention group at the seven month follow up because of the learnt consultation styles. Other measures of competency were included to accommodate this unavoidable source of error.

Our study shows the potential of doctors to respond to the changing health needs of youth after brief training based on a needs analysis and best evidence based educational practice. Further study should address the extent to which these changes in doctors' competence translate to health gain for their young patients.

We thank the participating doctors, Helen Cahill (Youth Research Centre, Melbourne University), Dr David Rosen (University of Michigan), and Sarah Croucher (Centre for Adolescent Health).

Contributors: LAS, the prinicipal investigator, initiated and conducted the intervention and wrote the paper. CC advised on recruitment, randomisation, pilot testing of instruments, and data analysis and helped write and edit the paper. FV provided advice, participated in pilot testing of instruments, provided the medical rater's assessment of doctors' skill, and helped edit the paper. MC-G helped to design and deliver the intervention and to edit the paper. GP advised on the study design and helped write and edit the paper. ND was a supervisor to LAS and advised on the evaluation methodology and helped edit the paper. GB was the chief supervisor to LAS and advised on the intervention design and evaluation and helped edit the paper. LAS will act as guarantor for the paper.

Funding: The Royal Australian College of General Practitioners Trainee Scholarship and Research Fund and the National Health and Medical Research Council.

Competing interests: None declared.

1 Donovan C, Mellanby AR, Jacobson LD, Taylor B, Tripp JH. Teenagers views on the general practice consultation and provision of contraception. The adolescent working group. Br I Gen Pract contraception.

2 Oppong-Odiseng ACK, Heycock EC. Adolescent health servicesthrough their eyes. Arch Dis Child 1997;77:115-9.

3 Ginsburg KR, Slap GB. Unique needs of the teen in the health care setting. Curr Opin Pediatr 1996;8:333-7.

4 Veit FCM, Sanci LA, Young DYL, Bowes G. Adolescent health care: perspectives of Victorian general practitioners. Med J Aust 1995;163:16-8.

5 McPherson A, Macfarlane A, Allen J. What do young people want from their GP? [Letter] BrJ Gen Pract 1996;46:627.
6 Bearinger LH, Gephart J. Interdisciplinary education in adolescent health.J Paediatr Child Health 1993;29:10-5S.

7 Bennett DL. Adolescent health in Australia: an overview of needs and approaches to care. Sydney: Australian Medical Association, 1984.

8 Veit FCM, Sanci LA, Coffey CMM, Young DYL, Bowes G. Barriers to effective primary health care for adolescents. Med J Aust 1996:165:131-3. adolescent care. J Med Educ 1987;62:401-7.

10 Blum RW, Bearinger LH. Knowledge and attitudes of health professionals toward adolescent health care. J Adolesc Health Care 1990;11:289-94.

11 Resnick MD, Bearinger L, Blum R. Physician attitudes and approaches to the problems of youth. Pediatr Ann 1986;15:799-807

12 Davis DA, Thomson MA, Oxman AD, Haynes RB. Changing physician performance. A systematic review of the effect of continuing medical education strategies. JAMA 1995;274:700-5.

13 Davis DA, Thomson MA, Oxman AD, Haynes RB. Evidence for the effectiveness of CME. JAMA 1992;268:1111-7.

14 Oxman AD, Thomson MA, Davis DA, Haynes RB. No magic bullets: systematic review of 102 trials of interventions to improve professional practice. Can Med Assoc J 1995;153:1423-31.

15 Owen JM. Program evaluation forms and approaches. St Leonards, NSW: Allen and Unwin, 1993

16 Davis D, Fox R. The physician as learner. Linking research to practice. Chicago, IL: American Medical Association, 1994

17 Greene JC, Caracelli VJ. Advances in mixed-method evaluation: the challenges and benefits of integrating diverse paradigms. New directions for evaluation, No 74. San Francisco: Jossey-Bass, 1997.

18 Masters GN, McCurry D. Competency-based assessment in the professions. Canberra: Australian Government Publishing Service, 1990.

19 Norman GR, Neufeld VR, Walsh A, Woodward CA, McConvey GA Measuring physicians' performances by using simulated patients. $J$ Med Educ 1985;60:925-34

20 Woodward CA, McConvey GA, Neufeld V, Norman GR, Walsh A Measurement of physician performance by standardized patients. Refining techniques for undetected entry in physicians' offices. Med Care 1985;23:1019-27.

21 Rosen D. The adolescent interview project. In: Johnson J, ed. Adolescen medicine residency training resources. Elk Grove Village, IL: American Academy of Pediatrics, 1995; 1-15.

22 The Royal Australian College of General Practitioners College examination handbook for candidates 1996. South Melbourne: Royal Australian College of General Practitioners, 1996.

23 Hays RB, van der Vleuten C, Fabb WE, Spike NA. Longitudinal reliability of the Royal Australian College of General Practitioners certification examination. Med Educ 1995;29:317-21.

24 Bridges-Webb C, Britt H, Miles DA, Neary S, Charles J, Traynor V. Morbidity and treatment in general practice in Australia 1990-1991. Med JAust 1992;157:1-57S

25 The general practices profile study. A national survey of Australian general prac tices. Clifton Hill, Victoria: Campbell Research and Consulting, 1997.

26 Knowles M. The adult learner. A neglected species. Houston, TX: Gulf, 1990.

27 Ward J. Continuing medical education. Part 2. Needs assessment in continuing medical education. Med J Aust 1988;148:77-80.

28 Norman GR. Defining competence: a methodological review. In: Neufeld VR, Norman GR, eds. Assessing clinical competence. New York, NY: Springer, 1985;15-35.

29 Rethans JJ, Strumans F, Drop R, van der Vleuten C, Hobus P. Does competence of general practitioners predict their performance? Comparison between examination setting and actual practice. BMJ 1991;303:1377-80.

30 Pieters HM, Touw-Otten FWWM, De Melker RA. Simulated patients in assessing consultation skills of trainees in general practice vocational training: a validity study. Med Educ 1994;28:226-33.

31 Colliver JA, Swartz MH. Assessing clinical performance with standardized patients. JAMA 1997;278:790-1.

32 Colliver JA. Validation of standardized-patient assessment: a meaning for clinical competence. Acad Med 1995;70:1062-4.

(Accepted 7 October 1999)

\section{One hundred years ago National enthusiasm and alcohol}

The national joy over the recent successes of our arms in South Africa is apt, as the records of the police-courts show, to express itself in an increased consumption of ardent liquors. Such a mode of showing patriotic enthusiasm may be gratifying to the Chancellor of the Exchequer, but we may be permitted to doubt whether this public-spirited consideration entered largely into the minds of the thousands who got drunk in honour of the relief of Mafeking and the capture of Pretoria. If these events caused such a copious pouring of libations of beer and whisky, it is easy to forecast what will happen when the final triumph comes. As regards the general population doubtless the fundamental good sense of the British public may be trusted to prevail sufficiently to avert the anger of a pandemic of acute alcoholism. But there is a class of the community which, it is to be feared, will be subjected to very serious risk. Already complaints have found utterance that the sailors of the Powerful got too much to drink, although, as far as we know, there is no suggestion that they were appreciably the worse for it. It is to be feared that when the rest of our conquering heroes come home almost irresistible temptations to drink will meet them on every side. It may seem puritanical to seek to repress a very natural manifestation of feeling, and one, too, that is consecrated by national custom. Enlightened patriots however, as well as moralists and hygienists, will agree that the custom is more honoured in the breach than in the observance. Of all possible ways of showing our admiration for the courage and devotion of the men who have been fighting their country's battles, surely the very worst is to poison and brutalise them with drink. (BMJ 1900;i:1604.) 


\title{
Commentary: Applying the BMJ's guidelines on educational interventions
}

\author{
Jean Ker
}

Clinical Skills Centre, University of Dundee,

Ninewells Hospital and Medical School, Dundee DD1 9SY

Jean Ker

lecturer in medical

education

jsker@dundee.

ac.uk
In the western world, healthcare systems are facing enormous changes driven by both political and economic forces and by the increase in consumer expectations for competent and consistent quality health care. In response to these changes, medical education has become an increasingly important aspect of every doctors' professional life. Publishers have responded by including papers on medical educational issues with increasing frequency. This move has, however, required the development of guidelines to evaluate papers on educational interventions.

This critique applies guidelines developed by the $B M J$ s education group, which were published in the BMJ on 8 May 1999.

\section{Guideline 1: General overview}

The commitment of the BMJ to publish more educational research makes the paper by Sanci et al an eminently suitable one for practising doctors interested in medical education.

Adolescent health care is challenging not only for general practitioners but for healthcare professionals involved in service delivery at all levels. This paper shows how successfully continuing medical education can be incorporated into changes in service delivery.

The principle steps of the educational intervention process are clearly outlined and can be generalised to other clinical settings, making it of interest to a wide readership. It contributes to the growing literature on evaluation of educational interventions in the general practice setting by attempting to show sustained changes in practice performance after a brief programme for continuing medical education.

The paper also follows the general style and guidelines for publication in the $B M J$.

\section{Guideline 2: Theoretical considerations}

One of the purposes of the guidelines on evaluating educational interventions is to facilitate, through papers, readers' understanding of the teaching and learning process so that they can apply any relevant aspects to their own practice.

In relation to this, the goals of this educational intervention are well described in the context of Australian general practice. The educational rationale was, however, rather brief in its explanation. An expanded discussion on the strategies used could have covered advantages and disadvantages. Readers may be able to utilise some of the learning opportunities given, but their links to the goals were not explicit.

\section{Guideline 3: Study presentation and design}

A panel of stakeholders, including patients, was used to identify the content and design of the multifaceted intervention, which ensures the relevance of the intervention in terms of healthcare practice, and this was described in detail. The study design to ensure that standardised patients and observers were blind to the intervention status of the doctors is commendable.

In answering the questions posed in the guidelines some concerns with the design are raised.

The study is described as a randomised controlled study. A better and less misleading description would have been to describe it only as a randomised study, as it is often difficult to eliminate contaminants in an educational intervention. In fact the bias described in the type of practice, the language spoken, the age differences, as well as the college exams taken, does question the positive outcomes reported in the study.

The lack of a pretest to identify whether the two groups were comparable in terms of knowledge does also bring into question the final interpretation of the intervention. Purposive sampling based on a pretest and the variables described above would have been more appropriate and would have lent more meaning to the outcome.

The statistical analysis is clearly shared with the reader and well described. The use of a multifaceted evaluation system using recognised validated instruments reflects the guidelines for evaluating papers on educational interventions.

\section{Guideline 4: Discussion}

The discussion was structured in accordance with the guidelines, with a clear statement of the principle findings. The sustainability of the intervention could, however, have been highlighted as it was a significant finding. The strengths and weaknesses of the study in relation to selection bias were well debated and justified.

The discussion in relation to other studies was, however, only briefly addressed, referring to only one systematic review of strategies for continuing medical education. This could have been expanded to support some of the findings, particularly in relation to the rapport and satisfaction of the standardised patients as a measurement of outcome.

The discussion did not begin to explore the implications for clinicians other than to indicate a need for assessing the health gain for patients from such interventions but did not discuss the difficulties of cost benefit analysis.

The guidelines on evaluating educational interventions as applied to this paper enabled the reviewer to systematically address all relevant aspects of the intervention. What is not clear is how much weighting should be placed on each guideline in relation to deciding whether the article should be published or not. 